\title{
Enhanced Gesture Recognition Text to Speech Browser for Visually Challenged
}

\author{
M. Rajesh Khanna, C. Thirumalai Selvan
}

\begin{abstract}
Web has understood an astonishing change in human access to learning and information. The need of plotting an upgraded program for the ostensibly tried. The present structure helps the apparently tried people to use the information in the web satisfactorily, by changing over the substance in the site page to voice for their better use. The customer can look through the substance and indispensable information from the web by simply composing the URL. The site page substances are removed by JSOUP HTML parser. The isolated substance will be scrutinized out by Text to Speech (TTS) engine. The weights in this system are the apparently tried need to type URL the required in the change box, there are no contrasting options to control TTS and there are no decisions for investigating through site pages. The proposed structure is to arrange talk affirmation engine.
\end{abstract}

Keywords: Web Browser for stupor; content upgrade; substance to-talk

\section{INTRODUCTION}

With the progress in advancement and the redesign of the World Wide Web, information of various kinds has accomplished the doorstep of people wherever all through the world Individuals can take in anything and access news from wherever all through the world sitting agreeable homes through the Internet. In any case, the apparently tried people are prevented from claiming this favorable position.

Due to their disappointment in getting to information from formed substance records, ostensibly tried face tremendous difficulties in getting to information through web. Along these lines, to give proper information get to and to interface the correspondence gap between the apparently tried and the found gathering, the need to fabricate some advance mechanically reinforced structures

\section{EXISTING IMPLEMENTATION AND DISADVANTAGE}

Different undertakings were made worldwide to build web projects and update usability of web for the ostensibly injured people. In this paper we have through and through considered without a doubt the most by and large used web programs for the blinds. Further, we have taken a gander at each one of the projects in perspective of their key GUI features. In light of our examination we consider the going with GUI features to be essential for a web program for the blinds. Next, we will discuss a bit of the consistently used web programs for the visual weakened people. Among the early undertakings, voice data and commitment for surfing was grasped for the ostensibly debilitated people.

Presentation page Reader, among others, demonstrates the site page in an easy to-use interface, and adherents the substance to talk, having different sexual introduction voices for examining works and associations. Regardless, the obstruction of this is the specialist needs to design a complex new interface for the complex graphical site pages to be examined and for the screen peruser to see. Since basically voice data and yield did not deal with the issue of usability of the web for the apparently debilitated people, tries to re-structure site pages grabbed reputation. progresses a direct scrutinizing plan, which secludes a site page into two estimations. This remarkably unravels a page's structure and makes it less requesting to scrutinize.

In any case, on account of the multifaceted nature and grouped assortment of webpage pages, this structure did not fill in as all site pages couldn't be modified. Another web program delivered a tree structure from the HTML record through analyzing joins.

Notwithstanding the way this attempted to structure the pages that are associated together to enhance security, this did not exhibit to a great degree capable for surfing. Also, it didn't manage issues with respect to wellbeing and accommodation of the present page itself.

\section{DISCOURSE RECOGNIZER FRAMEWORK}

The proposed framework is to build up a program that acknowledges voice input. A discourse recognizer framework is utilized that perceives the discourse and changes over the discourse into content. The client can peruse the website page by giving discourse input.

Revised Manuscript Received on December 30, 2019.

* Correspondence Author

M. Rajesh Khanna*, Information Technology, Veltech Multitech Dr. Rangarajan Dr. Sakunthala Engineering College, Chennai (Tamil Nadu) India. E-mail: rajeshkhanna@veltechmultitech.org

C. Thirumalai Selvan, department of CSE, Sri Indu Institute of engineering and technology, Sheriguda, Ibrahimpatnam (Telangana) India. E-mail: thirumalaiselvan@outlook.com

(C) The Authors. Published by Blue Eyes Intelligence Engineering and Sciences Publication (BEIESP). This is an open access article under the CC BY-NC-ND license (http://creativecommons.org/licenses/by-nc-nd/4.0/) 


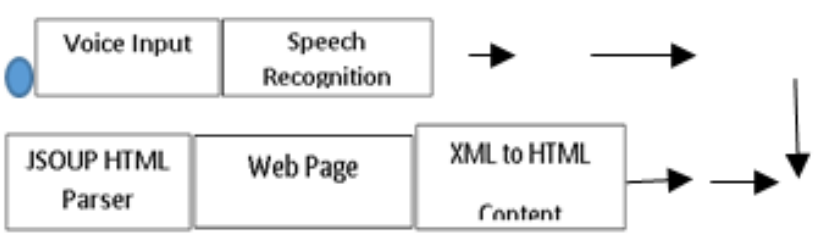

Text to Speech
System

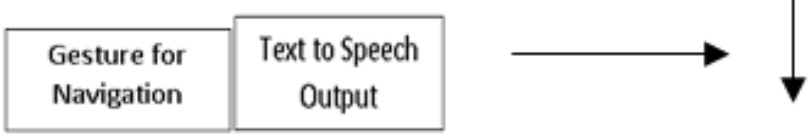

\section{Navigation Via}

Web Page

Fig.1. Work flow diagram of proposed system

The JSOUP HTML parser change over the site page content into html substance and concentrates the substance from the HTML changes over and demonstrate those in the substance see. The TTS engine changes over those works into talk yield. Signs can be performed on the substance see for basic course. Voice Input Operations on the program, which are generally performed by mouse clicks, can be performed by talk arranges, A talk recognizer is fused with the program, which is set up to see each one of the requests a talk recognizer structure is composed into the program which recognizes. The voice data and adherents those into content. These assistants the apparently tried easily look through the substance in the program rather than using mouse and comfort. The JSOUP HTML parser removes the substance from the website page and changes over those web substance to HTML substance. These changed over html substance are appeared in the substance see. A Text to Speech structure is made out of two segments: a front-end and a back-end. The front-end has two important assignments. In the first place, it changes over rough substance containing pictures like numbers and shortenings into what should be gotten formed out words. This strategy is regularly called content institutionalization, pre-dealing with, or tokenization. The front-end allots phonetic Transcriptions to each word, and parcels. It signifies the substance into prosodic units, like articulations, stipulations, and sentences; the route toward doling out phonetic interpretations to word is called substance to-phoneme or grapheme-to-phoneme safeguarding change. Phonetic understandings and prosody information together make up the significant semantic depiction that is yield by the front-end. The back-end as often as possible insinuated as the synthesizer by then changes over the meaningful etymological depiction into sound. In particular systems, this part joins the computation of the goal prosody (pitch frame, phoneme ranges) yield.

\section{METHODOLOGY}

\section{A. Speech to Text}

Dialect is a quick and viable method for conveying. To utilize dialect intends to express a boundless measure of thoughts, musings and useful data by joining a constrained measure of words with the assistance of a restricted measure of syntactic principles. The aftereffect of dialect creation forms are arrangement of words and structure. Arrangements of words are delivered talked or marked - in an extremely fast and successful way. Any individual can take after such dialect creation forms and comprehend what the individual needs to express if two preconditions are satisfied the beneficiaries must:

1. Know the words and linguistic tenets the speaker uses and 2. Have the capacity to get and process the physical signal. Most individuals utilize oral dialect for regular correspondence, i.e. they address other individuals and hear what other individuals say. Individuals who are hard of hearing or almost deaf don't have measure up to access to talked dialect, for them, precondition 2 isn't satisfied; their capacity to get discourse is impaired. If individuals who are extremely debilitated in their listening ability capacities need to participate in oral correspondence, they require an approach to remunerate their physical impairment1.

Amplifiers are adequate for some, hearing weakness individuals. Be that as it may, if amplifiers are deficient, talked dialect must be moved into a methodology which is open without hearing.

\section{B. Text to Speech Module}

A text-to-speech (TTS) engine is at the focal point of the talk yield age module. It is changes over strings of substance to their relating human voice approach. Remembering the true objective to develop the proposed transliteration plan, we used a substance to-talk engine called Shruti that uses diphone association with join talk in Indian lingos using. The Shruti substance to-talk engine starting at now supports two Indian tongues specifically Hindi and Bengali. We created a wrapper around the TTS engine with the objective that it can be used by different applications including our transliteration system. The wrapper moreover gives different other key features like Transformation of substance in Unicode or iTrans to ISCII1 Pronunciations of individual and conjugate characters. Which is the neighborhood depiction arrangement of the TTS being used.

\section{Gesture Input and Recognition Module}

The JSOUP HTML parser removes the substance from the site page and recoups the substance in the substance see. The substance in the substance see is scrutinized out by the TTS engine. The TTS engine scrutinizes out the whole substance in the substance see instantly.

The critical burden is that the ostensibly tried doesn't have any choices for granularity change. If the TTS engine starts to scrutinize the substance in the substance see, it will stop exactly at the last word.

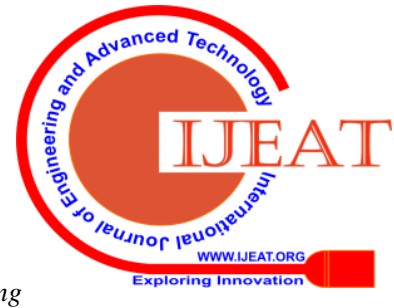


In case the apparently tried requirements to hear a comparative word or same sentence; they won't have options for that. Movements can be used to offer decisions to granularity change. Android offers customers to show their own movements and they can use that in their application and give exercises according to the application. A touch screen empowers a customer to interface with an in various a larger number of courses than is possible with a keypad. Customers can tap, drag, journey, or slide visual segments in order to play out an arrangement of assignments. The Android framework makes seeing essential material data basic, for instance, a swipe, however seeing more personality boggling signals is all the more troublesome. Android and later joins the packageandroid.gesture. For complex flag affirmation. This API stores, loads, draws, and sees gestures.on. The signs can be displayed using Signal Builder Application. By using Gesture Builder, the customer can display their own specific flags and name them. The signs are secured in the sd card at the zone File Explorer/mnt/sdcard/movements. The movements record can be pulled to our wander by a coordinator rough as res/unrefined.

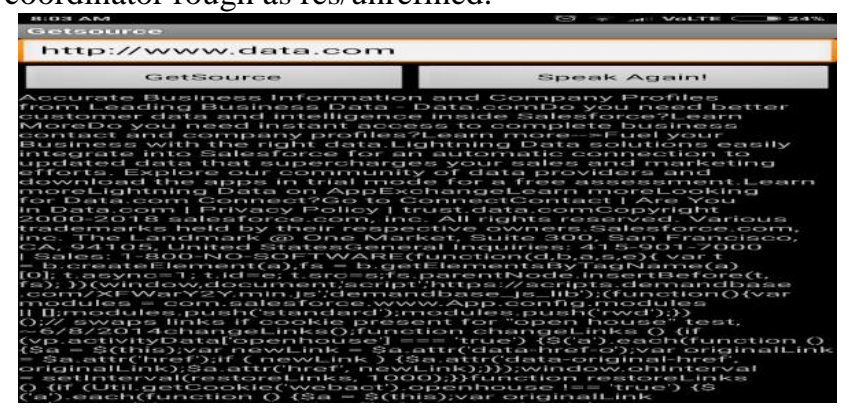

Fig.2. Retrieval of Content

After getting the URL, the JSOUP HTML parser extracts the contents from the page and displays those in the text view.

The above figure shows the extracted contents from the web page

\section{RESULTS AND DISCUSSIONS}

The gestures are used here for navigation. We can stop, start and make TTs to read from the beginning from where it paused. The following table shows the user interface of the newly created browser.

Table-1: Gesture recognition

\begin{tabular}{|c|c|c|}
\hline \multirow{2}{*}{$\begin{array}{c}\text { Gestu } \\
\text { re } \\
\text { Word } \\
\text { s }\end{array}$} & \multicolumn{2}{|c|}{$\begin{array}{c}\text { TTS engine with Gesture } \\
\text { Recognition }\end{array}$} \\
\hline & $\begin{array}{c}\text { Symbo } \\
\text { I }\end{array}$ & Use \\
\hline Start & Circle & $\begin{array}{l}\text { Gesture to Start TTS from } \\
\text { Beginning }\end{array}$ \\
\hline Stop & line & Gesture to stop TTS \\
\hline
\end{tabular}

The following Figures shows the gesture to start TTS.

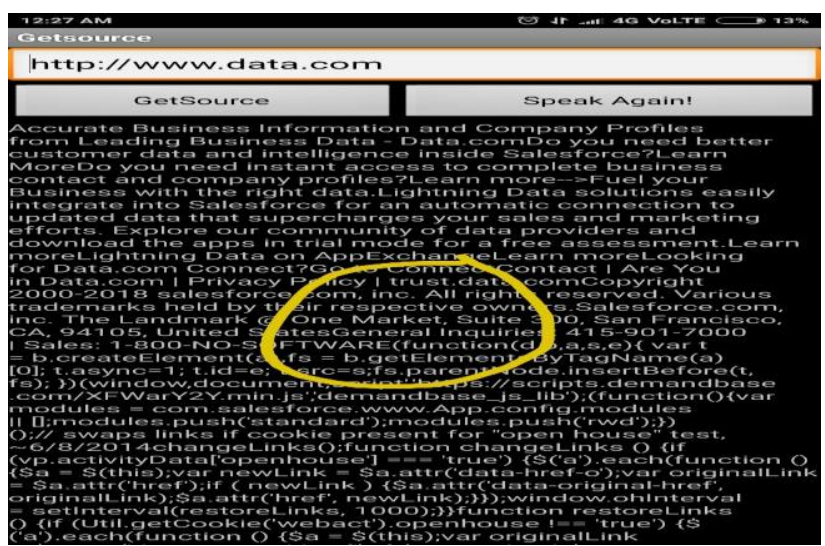

Fig.3. Gesture to start TTS

The following Figures shows the gesture to stop TTS.

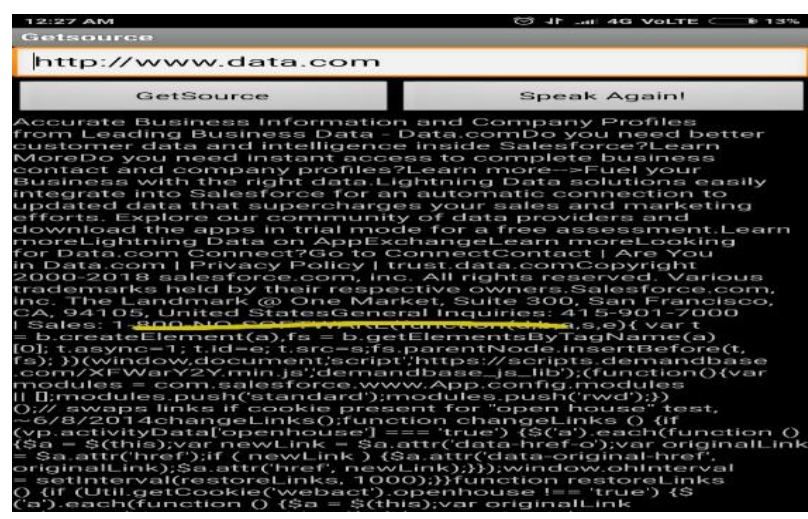

Fig.4. Gesture to stop TTS

The present system helps the apparently tried people to use the information in the web sufficiently, by changing over the substance in the site page to voice for their better utilize. The customer can look through the substance and essential information from the web by simply forming the URL. The site page substances are isolated by JSOUP HTML parser. The expelled substance will be scrutinized out by Text to Speech (TTS) engine. The downsides in this structure are the apparently tried need to type the required URL in the modify box, there are no contrasting options to control TTS and there are no decisions for investigating through site pages. The proposed system is to organize talk affirmation engine. It sees the voice and changes over the voice commitment to content. This urges the ostensibly tried to easily examine in the web. By giving signs they can without a lot of an extend investigate through site pages and can control TTS. This system replaces other existing structures, which influences them to work the PC and use to web basically and subsequently benefits their lives.

\section{CONCLUSSION}

The weights in this system are the apparently tried need to type URL the required in the change box, there are no contrasting options to control TTS and there are no decisions for investigating through site pages. The proposed structure is to arrange talk affirmation engine. It sees the voice and changes over the voice commitment to content. This urges the apparently tried to successfully examine in the web.

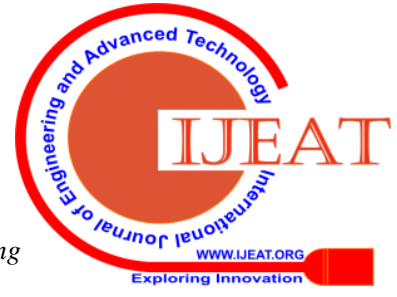




\section{Enhanced Gesture Recognition Text to Speech Browser for Visually Challenged}

By giving signs they can without a lot of an extend investigate through site pages and they can control.

\section{REFERENCE}

1. "The Android Source Code: Governance Philosophy". Nsource.android.com., 2014.

2. Rupali and Dharmale ,"Text Detection and Recognition with Speech Output for Visually Challenged Person"e, Research GateInternational Journal of Engineering Research and Applications, Vol. 5, Issue. 3, 2015, pp.84-87

3. AlexandreTrilla and Francesc Alías , "Sentence-Based Sentiment Analysis for Expressive Text-to-Speech", IEEE Transactions on Audio, Speech, and Language Processing, Vol. 21, Issue. 2. ,2013, pp. 223-233.

4. Jayshree Katkar , Omkar Kahane, Vivek Jadhav, Pratik Jadhav, "Hand Gesture Recognition And Device Control" , IJETSR, ISSN 2394 - 3386 Volume 4, Issue 4, 2017.

\section{AUTHORS PROFILE}

M. Rajesh Khanna has received Ph.D degree on 2019.Currently working as Associate Professor in Veltech Multitech Dr.RR Dr.SR Engineering college,avadi,Chennai,india. He has 10 years of teaching experience and has published 10 international

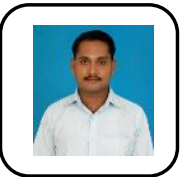

Dr. C. Thirumalai Selvan is currently working as Professor in the department of Computer Science and Engineering at Sri Indu Institute of Engineering and Technlogy, Telangana, India. He received Ph.D from Anna University in the department of Computer Science and Engineering. He received M.Tech from SRM University and B.E. from Anna University, India in 2009 and 2006. He has more than 10 years of teaching experience and has published more than 9 international journals on the field of Cloud Computing. He is life time member of ISTE. 